\title{
DISSOLUTION AND BIODEGRADATION KINETICS OF WATER EXTRACTABLE ORGANIC CARBON FROM MUNICIPAL SOLID WASTE UNDER VARIOUS CONDITIONS
}

\author{
Chuanfu WU ${ }^{1 *}$, Takayuki SHIMAOKA ${ }^{2}$, Teppei KOMIYA ${ }^{2}$ and Gangzhen JIAO ${ }^{1}$ \\ ${ }^{1}$ Department of Urban and Environmental Engineering, Graduate School of Engineering, Kyushu University \\ (744, Motooka, Nishi-ku, Fukuoka, 819-0395, Japan) \\ ${ }^{2}$ Department of Urban and Environmental Engineering, Faculty of Engineering, Kyushu University \\ (744, Motooka, Nishi-ku, Fukuoka, 819-0395, Japan) \\ "E-mail: wuchuanfu83@ hotmail.com
}

\begin{abstract}
Understanding the effects of environmental conditions (e.g. temperature and $\mathrm{pH}$ value) on organic carbon dissolution behavior is very important for quantifying the biodegradation of municipal solid waste. However, the dissolving of organic carbon from solid waste has not been sufficiently described. In this paper, the dynamic of organic carbon dissolution under different temperature and $\mathrm{pH}$ value conditions are analyzed by both experiment data and model simulation. The results revealed that lower leaching $\mathrm{pH}$ values are favor for dissolving organic carbon especially rapidly dissolution fraction of the solid samples. Under high temperature extraction condition, the dissolution rate of rapidly dissolution fraction was also improved and the amounts of biodegradable products exceed low temperature extraction amount. The dissolving rates of organic carbon were in the order of $0.045-0.22 \mathrm{~m}^{3} / \mathrm{kg} / \mathrm{h}$ for all leaching conditions. The labile fractions of water extractable organic carbon were ranged from $3.5 \%$ to $20.3 \%$. Therefore, the water extractable organic carbon extracted from MSW consists of substantial amount of stable fraction, indicating that anaerobic bioremediation of old landfill site is ineffective.
\end{abstract}

Key Words: Municipal solid waste; water extractable organic carbon; Environmental conditions; Numerical modeling; Biodegradability

\section{Introduction}

In Asian countries, Municipal Solid Waste (MSW) landfills are generally operated by conventional landfilling techniques, where anaerobic conditions are created within the landfill waste ${ }^{1)}$. Biodegradation of organic matter under anaerobic conditions is a slow process and therefore it may bring risks to human health and the environment for a very long time. Biological stabilization of old landfills with in-situ aeration may accelerate the stabilization of the MSW and reduce the emission of greenhouse gases. The advantages of landfill aeration were demonstrated by lab-scale experiments ${ }^{2,3)}$ and further implement on the large-scale landfill site ${ }^{4,5)}$. Decomposition of solid organic matter in Aerobic-Anaerobic landfill system can be generally separated into three processes: organic carbon dissolution, hydrolysis and biodegradation ${ }^{6}$. Clarifying the dissolving behavior of organic carbon from solid waste was essential for further quantification the hydrolysis and biodegradation process.

Dissolved organic carbon (DOC) or more precisely water-extractable organic carbon (WEOC) plays a key role in understanding a wide variety of physical-chemical and biological processes occurring in landfill site since it has a strong influence on many ecologically relevant processes. The most common acknowledgement about DOC is that it can enhance the solubility and mobility of metal and affect the availability of nutrients such as $\mathrm{N}, \mathrm{P}$ and $\mathrm{S}^{7)}$. Also, WEOC might be the most important $\mathrm{C}$ source for microorganisms and all microbial uptake mechanisms require a water environment. Therefore, the soluble state is essential for diffusion of substrates through microorganism cell membranes so the decomposition of the solid organic matter or large molecules can only occur after dissolution or hydrolysis by exoenzymes ${ }^{8)}$.

In the past decades, much progress has been made in understanding of WEOC functions and dynamics in soils, composting and MSW biodegradation field. In soil field, researchers have found that although WEOC makes up a very small portion (sometimes less than $1 \%{ }^{9)}$ ) of total soil organic matter, it may provide the measure of bioavailable carbon. For example, Burford and Bremner $^{10)}$ found a strong connection between WEOC, the rate of carbon mineralization and denitrification using different surface soils. Similar results also obtained by Cook and Allen (1992) ${ }^{11}$. 
Also, the quality of the DOC/WEOC may strongly affect the physical characteristics (e.g. structure, aggregation) of soil ${ }^{12)}$. In composting and MSW biodegradation field, WEOC has been chosen to clarify the process involved in the attainment of stability and maturity during the decomposition of waste materials ${ }^{13)}$.

Although some studies have been conducted and information about the properties of WEOC has been widely obtained, the dissolution kinetics of WEOC from solid materials are still rarely seen. Some researchers mainly focus their more attention on establishing the model for dissolving behavior of specific compounds, such as $\mathrm{PAHs}^{14)}$ and $\mathrm{PCB}^{15)}$, than establishing the model for dissolution of organic carbon from solid waste. However, individual identification may not facilitate for constructing the biodegradation modeling for organic solid waste.

In this study, dissolving behaviors of organic carbon from MSW at various temperatures and $\mathrm{pH}$ values were investigated. Moreover, two different models, used to describe those dissolving phenomena were evaluated for the experimental data. Finally, biodegradations of WEOC under different extraction conditions were investigated. The objectives of this study were 2-fold: (i) to establish a numerical model which can simulate the dissolving behavior of organic carbon from MSW and provide information on long-term dissolution kinetics of WEOC; (ii) to investigate the biodegradability of these WEOC and feasibility of bioremediation of old landfill site.

\section{Materials and methods}

\subsection{Municipal solid waste}

Municipal solid waste samples used in leaching experiment were taken from Laogang landfill, Shanghai, China, which were received primarily from residential and some commercial raw MSW with a capacity of 9000 tons per day. These solid wastes have been decomposed anaerobically for five years before the sampling. Solid waste samples were collected from several random pits (approximate 1 meter) which were excavated with means of digger and then were mixed so that the most representative sample could be obtained. The original aged refuse comprised $1.0 \%(\mathrm{w} / \mathrm{w})$ of waste paper, $2.3 \%(\mathrm{w} / \mathrm{w})$ of cloth, $4.7 \%(\mathrm{w} / \mathrm{w})$ of plastic, $0.2 \%$ of rubber and leather, $6.5 \%(\mathrm{w} / \mathrm{w})$ of wood and straw, $6.0 \%(\mathrm{w} / \mathrm{w})$ of kitchen waste, $1.1 \%(\mathrm{w} / \mathrm{w})$ of metal, $6.6 \%(\mathrm{w} / \mathrm{w})$ of glass, $28.7 \%(\mathrm{w} / \mathrm{w})$ of ceramics and stone, $42.9 \%$ $(\mathrm{w} / \mathrm{w})$ of the others whose sizes were lower than 5 $\mathrm{mm}$. More information about the characteristics of this municipal solid waste can be found elsewhere 16)
The excavated aged solid samples were sieved moistly (lower than $4 \mathrm{~cm}$ ) in situ and large plant material and rock were removed by artificial selection. The subsamples were air-dried at room temperature, and were sieved to obtain the aggregate size fraction lower than $2 \mathrm{~cm}$. After that, the sieving samples were grinded until the aggregate size was lower than $0.44 \mathrm{~mm}$ with two-fold purposes: firstly, the amount of solid waste used to process the leaching experiment was just 5 gram and the grinding procedure would guaranty the homogeneity of the sample. Secondly, the grinded samples can represent samples whose sizes were lower than $2 \mathrm{~cm}$, and are of more representation than the particle diameter lower than $2 \mathrm{~mm}$. The grinded samples were stored at $4^{\circ} \mathrm{C}$ prior to leaching experiments. The $\mathrm{pH}$ of the solid sample was 9.0 \pm 0.2 , dry-weight percentage of total carbon, total inorganic carbon and the total nitrogen were $9.5 \pm$ $0.5 \%, 1.4 \pm 0.1 \%, 0.6 \pm 0.1 \%$, respectively.

\subsection{Leaching experiments}

One objective of our experiments was to investigate the influence of different temperatures $\left(25,35\right.$ and $\left.45{ }^{\circ} \mathrm{C}\right)$ and $\mathrm{pH}$ values $(7,8$ and 9$)$ on organic carbon leaching behavior. Leaching experiments were processed in several 1L beakers which were set on the heaters. Each beaker was loaded with $5 \mathrm{~g}$ of grinded sample and $1 \mathrm{~L}$ deionized water. The desired temperatures and $\mathrm{pH}$ values of the solution were adjusted and maintained by the heaters and $5 \mathrm{mM} \mathrm{HCl} / \mathrm{NaOH}$ solutions, respectively. A stirring apparatus was installed to keep the solid sample suspension during the leaching experiments with the stirring rate of $300 \mathrm{rpm}$. During the experiments, $15 \mathrm{ml}$ solutions were sampled with syringed equipped with $0.45 \mu \mathrm{m}$ cellulose acetate membrane filter at different time interval. Each of leaching experiments was processed for 6 hours which are in agreement with leaching test method for soil, JLT-46 ${ }^{17)}$. All the leaching experiments were carried out in duplicate.

\subsection{Incubation experiments}

$400 \mathrm{ml}$ of the solution extracted from different batch experiments were used to quantify the potential biodegradability of WEOC. As shown in Figure 1, the incubation experiments were processed in $500 \mathrm{ml}$ flasks. No nutrients were added during the whole experiment. We used the original samples (< $4 \mathrm{~cm}$ ) to obtain the inoculums which ensured the equivalent start conditions. Before extraction of inoculums, the solid sample (moisture 65\%) was incubated for 14 days at $30{ }^{\circ} \mathrm{C}$ to reactivate the microorganisms. After that, inoculums solution was obtained by shaking the solid samples 1 hour with 4 $\mathrm{mM} \mathrm{CaCl} 2$ solution (Solid: Solution =1:10) and 
filtered through $5 \mu \mathrm{m}$ membrane filter to remove large particles and grazing microfauna. The inoculums were added into the samples with inoculums/sample volume ratio of 1:100. Before the incubation, the $\mathrm{pH}$ values of inoculated samples were adjust to 9.0 with $5 \mathrm{mM} \mathrm{NaOH}$ solution and the top space of the flasks were purged with nitrogen gas to maintain the anaerobic condition. After that, inoculated flasks were incubated in the dark at $35^{\circ} \mathrm{C}$. The flasks were shaken once a day artificially. Subsamples $(15 \mathrm{ml})$ were collected from the incubation flasks at 1, 5, 12, 20, 28 days and passed through a $0.45 \mu \mathrm{m}$ filters. The filtrated solutions were analyzed immediately for total and inorganic carbon on a Shimadzu TOC analyzer. The biodegradation dynamic of WEOC were quantified by the flux of TOC concentration in liquid phase.

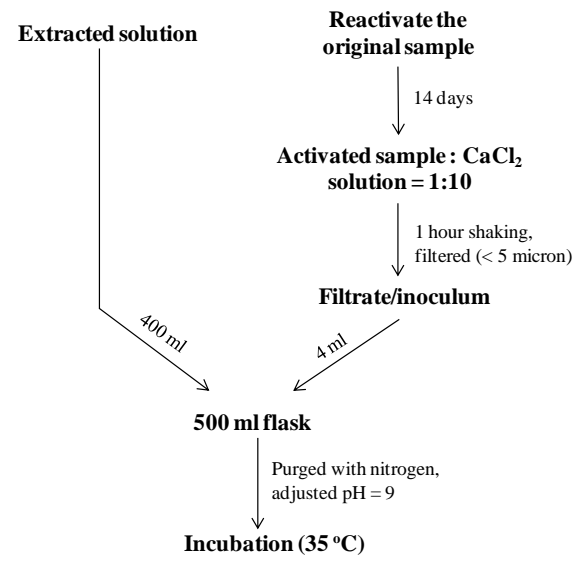

Fig. 1. Procedures of incubation experiments.

\subsection{Mathematic simulation}

\subsubsection{Leaching data simulation}

Two models variously which were used to describe leaching phenomena were evaluated for description of the rate data. Brief descriptions of these models are as follow.

The first evaluated model was a dynamic model which is considered to be the impact of organic carbon concentration in both solid and liquid phase. These equations have been used to simulate the biodegradation of MSW in Aerobic-Anaerobic landfill method ${ }^{6}$. Equations as follows have the forms

$$
\begin{aligned}
& \frac{\partial C_{C, S}}{\partial t}=-\beta C_{C, S}\left(C_{C, e q, l}-C_{C, l}\right) \\
& \frac{\partial C_{C, l}}{\partial t}=\frac{\varepsilon_{s} \beta}{\varepsilon_{l}} C_{C, S}\left(C_{C, e q, l}-C_{C, l}\right)
\end{aligned}
$$

Where $C_{C, S}\left(\mathrm{~kg} / \mathrm{m}^{3}\right)$ is concentration of organic carbon in the solid phase, $C_{C, \text { eq. }}\left(\mathrm{kg} / \mathrm{m}^{3}\right)$ is the concentration of organic carbon in the liquid phase under equilibrium state. $C_{C, l}\left(\mathrm{~kg} / \mathrm{m}^{3}\right)$ is concentration of organic carbon in the liquid phase at time $\mathrm{t}, \beta\left(\mathrm{m}^{3} /\right.$ $\mathrm{kg} / \mathrm{h}$ ) is the dissolve rate of organic carbon from the solid phase, $\varepsilon_{s}$ is the volumetric ratios of solid phase, $\varepsilon_{l}$ is the volumetric ratios of liquid phase.

The second tested model was a two-compartment model including three parameters. In this model, first-order equations were used to describe the dissolution rate for both the rapidly dissolving fraction, $f_{l}$, and the slowly dissolving fraction, $f_{2}$. A similar two-compartment model has been widely used previously to simulated desorption of hydrophobic organic contaminants (HOCs) from soils or sediments ${ }^{18,19,20)}$. The two-compartment model was shown as below.

$$
\frac{S(t)}{S_{o}}=f_{1} \exp \left(-k_{f} t\right)+f_{2} \exp \left(-k_{s} t\right), f_{1}+f_{2}=1
$$

Where $S(t)(\mathrm{kg})$ is the amount of WEOC in solid phase after dissolving time $\mathrm{t}(\mathrm{h})$. And $S_{o}(\mathrm{~kg})$ is the amount of extractable organic carbon. The total extractable carbon amount was measured according to the method modified from both researcher Shao et al. (2009) ${ }^{21)}$ and Zsolnay. (2003) ${ }^{22)}$. Briefly, the grinded solid samples were extracted with $10 \mathrm{mM}$ $\mathrm{CaCl}_{2}$ (solid to water ratio of $1: 10$, w/v) for 24 hours in a horizontal shaker at room temperature. The suspensions were then filtrated through a $0.45 \mu \mathrm{m}$ membrane filter. $f_{l}$ and $f_{2}$ are the rapidly and slowly dissolving fraction. $k_{f}\left(\mathrm{~h}^{-1}\right)$ and $k_{s}\left(\mathrm{~h}^{-1}\right)$ are apparent first-order rate constant for the rapidly and slowly dissolving fractions, respectively.

\subsubsection{Biodegradation data simulation}

Based on the assumption that WEOC is a mixture of components with different degradation rates and different extents of degradability, we fitted a double exponential model with two distinct pools with different rates to the measured mineralization using a least square optimization method. This double exponential model has been widely used to simulate the mineralization of water extractable organic carbon from different types of solid waste and soil $23,24,25,26,27)$.

\section{WEOC mineralization (\% of total WEOC)}

$=a\left(1-\exp \left(-k_{1} t\right)\right)+(100-a)\left(1-\exp \left(-k_{2} t\right)\right)$

Where $t$ is time (day), a: is the part of WEOC that is rapidly decomposed (equal to labile WEOC fraction, \%), (100-a) is the part of WEOC that is slowly decomposed (equal to stable WEOC fraction, \%), $k_{1}$ and $k_{2}$ are respective decomposition rate constants of the labile and stable WEOC $\left(\mathrm{h}^{-1}\right)$.

\subsubsection{Data analysis}

The values of the parameters adopted in dynamic 

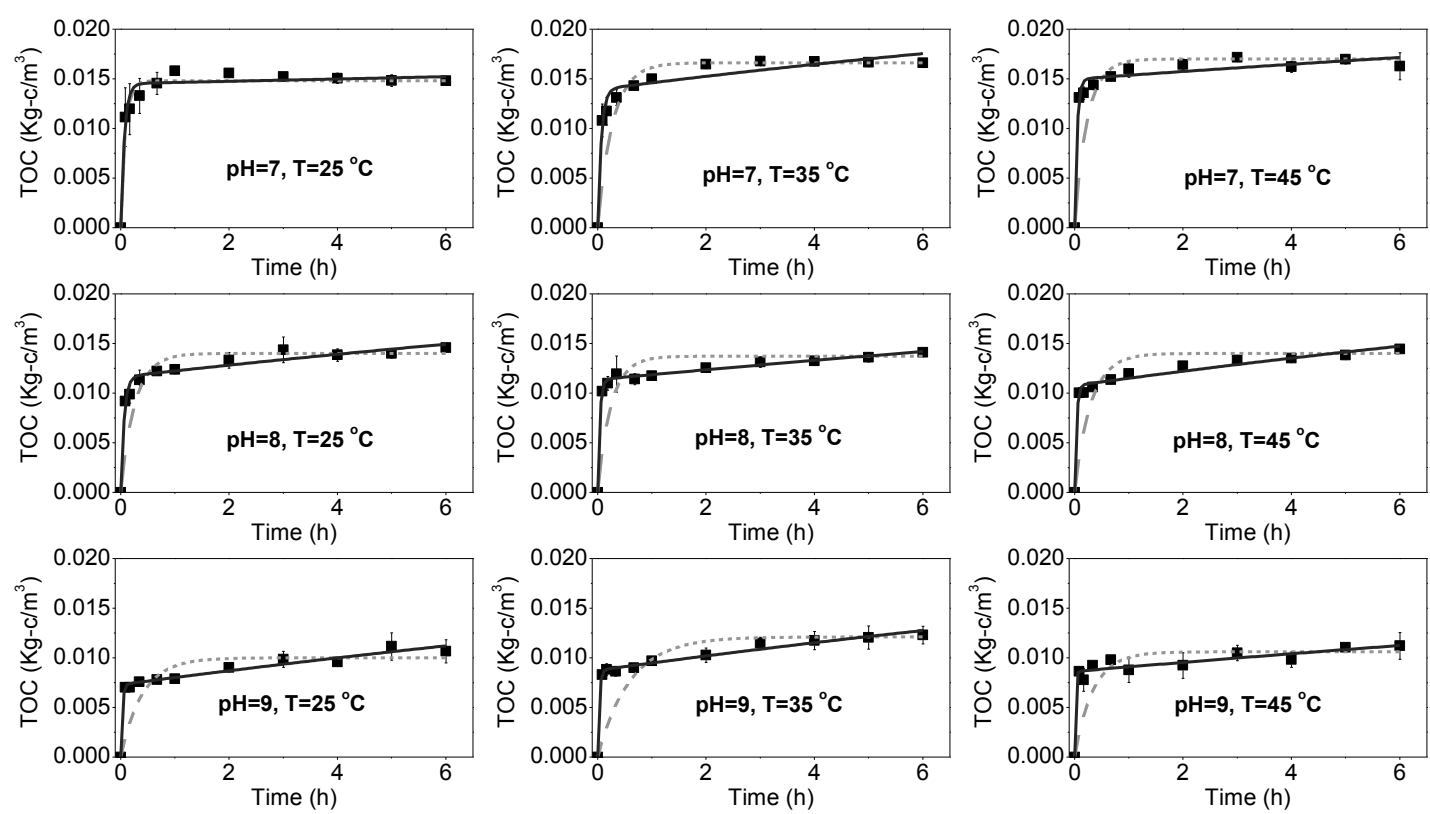

Fig. 2. Dynamics of organic carbon extraction under different leaching conditions. Black square represented for experimental data, short dot lines were dynamic model simulation, solid lines were two-compartment model simulation.

model were estimated by curve fitting with Finite Difference Method. The nonlinear regression of two-compartment models and double exponential model were developed with solver add-in tool. The solver tool was applied to maximize the coefficient of determination between experimental and predicted kinetics.

\section{Results}

\subsection{Effect of temperature and $\mathrm{pH}$ value on batch dissolution of organic carbon from MSW}

The values of organic carbon extracted from MSW under different extraction conditions have been shown in Figure 2. The values of dissolve rate and equilibrium concentration of organic carbon which were obtained by fitting the experiment data with dynamic model can be found in Table 1 . After 6 hours leaching experiment, the pseudostable equilibrium concentrations of WEOC were mainly affected by $\mathrm{pH}$ values other than temperatures. The average equilibrium concentration under $\mathrm{pH}$ value equal to 7 was $16.0 \times 10^{-3} \mathrm{~kg} / \mathrm{m}^{3}$. And the equilibrium concentration for $\mathrm{pH}$ value equal to 8 and 9 were $13.8 \times 10^{-3} \mathrm{~kg} / \mathrm{m}^{3}$ and $10.9 \times 10^{-3} \mathrm{~kg} / \mathrm{m}^{3}$, respectively. The dissolve rates of the organic carbon increased when the $\mathrm{pH}$ value decreased under the same temperature conditions. The dissolve rates were in the order of $0.45-2.2 \times 10^{-1} \mathrm{~m}^{3} / \mathrm{kg} / \mathrm{h}$ for all leaching conditions. However, the dissolve rates might not be very accurate because the dynamic model cannot match with the experiment data for the first 10 minutes. Therefore, the two-compartment model was used to investigate the leaching behavior of the solid sample.

In Table 2, the rapid fraction, rate constant for the rapidly and slowly dissolving fractions were given. The value of extractable organic carbon $\left(S_{o}\right.$, $\mathrm{mg}$ ) is $5.42 \mathrm{mg}$-c/g-solid sample which has been used in the leaching experiment. As can be seen in Table 2, the two-compartment model can fit the experiment data very well which can be reflected by the correlation coefficient. The rate constant for the rapid fraction $\left(k_{f}\right)$ increased with the rise of leaching temperature under the same $\mathrm{pH}$ condition while the rate constant for the slow fraction $\left(k_{S}\right)$ were affected by both temperature and $\mathrm{pH}$ conditions. The $k_{f}$ values were in the order of $14-65 \mathrm{~h}^{-1}$, which were around 1000 times larger than $k_{s}$. The value of rapid fraction $\left(f_{l}\right)$ increased with the reduction of liquid $\mathrm{pH}$ value under the same leaching temperature while it wasn't obviously affected by the temperature changing under the same $\mathrm{pH}$ conditions. The values of $f_{l}$ were about $50 \%, 40 \%$ and $30 \%$ for leaching $\mathrm{pH}$ value equal to 7,8 and 9 , respectively.

\subsection{WEOC mineralization}

The WEOC mineralization was shown in Figure 3. The mineralization fractions of the solution leaching from different conditions depended on both the leaching temperatures and $\mathrm{pH}$ value. Under $\mathrm{pH}$ value equal to 7 , the maximum mineralization fraction was $12.3 \%$ which appeared in leaching temperature equal to $45{ }^{\circ} \mathrm{C}$. For $\mathrm{pH}$ value equal to 8 
Table 1. Results of dynamic analysis of organic carbon dissolution (for the dynamic model).

\begin{tabular}{|c|c|c|c|c|c|c|}
\hline & \multicolumn{2}{|c|}{$\mathrm{T}=25^{\circ} \mathrm{C}$} & \multicolumn{2}{|c|}{$\mathrm{T}=35^{\circ} \mathrm{C}$} & \multicolumn{2}{|c|}{$\mathrm{T}=45^{\circ} \mathrm{C}$} \\
\hline & $\begin{array}{c}\beta \\
\left(10^{-1} \mathrm{~m}^{3} / \mathrm{kg} / \mathrm{h}\right)\end{array}$ & $\begin{array}{c}C_{e q} \\
\left(10^{-3} \mathrm{Kg} / \mathrm{m}^{3}\right)\end{array}$ & $\begin{array}{c}\beta \\
\left(10^{-1} \mathrm{~m}^{3} / \mathrm{kg} / \mathrm{h}\right)\end{array}$ & $\begin{array}{c}C_{e q} \\
\left(10^{-3} \mathrm{Kg} / \mathrm{m}^{3}\right)\end{array}$ & $\begin{array}{c}\beta \\
\left(10^{-1} \mathrm{~m}^{3} / \mathrm{kg} / \mathrm{h}\right)\end{array}$ & $\begin{array}{c}C_{e q} \\
\left(10^{-3} \mathrm{Kg} / \mathrm{m}^{3}\right)\end{array}$ \\
\hline $\mathrm{pH}=7$ & 2.2 & 14.8 & 0.9 & 16.6 & 1.1 & 16.6 \\
\hline $\mathrm{pH}=8$ & 1.0 & 14.0 & 1.0 & 13.7 & 0.9 & 13.7 \\
\hline $\mathrm{pH}=9$ & 0.7 & 10.0 & 0.5 & 12.1 & 0.8 & 10.6 \\
\hline
\end{tabular}

Table 2. Results of dynamic analysis of organic carbon dissolution (for the two-compartment model).

\begin{tabular}{|c|c|c|c|c|c|c|c|c|c|c|c|c|}
\hline & \multicolumn{4}{|c|}{$\mathrm{T}=25^{\circ} \mathrm{C}$} & \multicolumn{4}{|c|}{$\mathrm{T}=35^{\circ} \mathrm{C}$} & \multicolumn{4}{|c|}{$\mathrm{T}=45^{\circ} \mathrm{C}$} \\
\hline & $\begin{array}{c}K_{f} \\
\left(h^{-1}\right)\end{array}$ & $\begin{array}{c}K_{s} \\
\left(10^{-3} h^{-1}\right)\end{array}$ & $\begin{array}{l}f_{l} \\
(\%)\end{array}$ & $R^{2}$ & $\begin{array}{c}K_{f} \\
\left(h^{-1}\right)\end{array}$ & $\begin{array}{c}K_{s} \\
\left(10^{-3} h^{-1}\right)\end{array}$ & $\begin{array}{l}f_{1} \\
(\%)\end{array}$ & $R^{2}$ & $\begin{array}{c}K_{f} \\
\left(h^{-1}\right)\end{array}$ & $\begin{array}{c}K_{s} \\
\left(10^{-3} h^{-1}\right)\end{array}$ & $\begin{array}{l}f_{1} \\
(\%)\end{array}$ & $R^{2}$ \\
\hline $\mathrm{pH}=7$ & 14.8 & 9.5 & 53.1 & 0.96 & 15.3 & 53.0 & 50.9 & 0.97 & 22.8 & 32.6 & 54.8 & 0.98 \\
\hline $\mathrm{pH}=8$ & 16.0 & 39.4 & 42.6 & 0.98 & 26.5 & 32.6 & 41.6 & 1.00 & 29.6 & 45.7 & 39.4 & 0.99 \\
\hline $\mathrm{pH}=9$ & 36.0 & 36.2 & 26.7 & 0.98 & 34.6 & 40.5 & 32.0 & 0.99 & 65.6 & 25.2 & 31.6 & 0.97 \\
\hline
\end{tabular}

and 9 , the maximum mineralization fractions were $21.1 \%$ (under leaching temperature equal to $45{ }^{\circ} \mathrm{C}$ ) and $20.8 \%$ (under leaching temperature equal to 35 $\left.{ }^{\circ} \mathrm{C}\right)$.

The dynamic WEOC mineralization in most samples was fitted by a double exponential model (Table 3). The rate constants of the labile WEOC, $k_{l}$, increased when the leaching $\mathrm{pH}$ value decreased. The values of $k_{l}$ were significantly larger than the rate constants of the stable WEOC, $k_{2}$, although the value for $k_{2}$ may not be very accurate because of low number of sample points. The residence time (equal to $1 / k_{l}$ ) for labile organic carbon was ranging from 0.6-6.3 days. Furthermore, under $\mathrm{pH}$ value equal to 7 , the values of labile WEOC fraction, a (\%), were in order of $3.5 \%-11.0 \%$, which were much lower than other two leaching $\mathrm{pH}$ conditions. The labile fractions of WEOC rose when leaching temperature increased except in the case that $\mathrm{pH}$ value equal to 9 , temperature changed from $35{ }^{\circ} \mathrm{C}$ to $45^{\circ} \mathrm{C}$.

\section{Discussion}

Temperatures and $\mathrm{pH}$ values are variable during the decomposition of MSW. Understanding the dynamic of organic carbon extracted from solid waste is essential for further investigation of biodegradation process. The dissolution of organic carbon from solid waste is a very complicated procedure which can be affected by multi factors such as temperature and $\mathrm{pH}$ values ${ }^{28)}$. Dissolution of solid phase in liquid media usually proceeds in several steps, such as mass transfer process and chemical reactions of reactant with molecules located at the solid surface ${ }^{29)}$.

After 6 hours' leaching experiment, the pseudostable equilibrium concentrations of WEOC were mainly affected by $\mathrm{pH}$ value instead of temperatures. These results might be different from the common concept that solubility of the substance increased with the rising temperature. This phenomenon might be attributed to the following reasons. The rising temperature may increase the solubility equilibrium concentration and the effect was various with the specific compounds. The concentrations of WEOC in these experiments were much lower than the solubility equilibrium concentration and therefore the dissolving of organic carbon wouldn't stop if there was still extractable existing organic carbon existing. However, the results obtained by the experiments showed that the rising temperature didn't affect the equilibrium concentrations and therefore it might reveal the fact that the dissolution of specific organic compound (such as slowly dissolving fraction) which contributed to the equilibrium concentrations of WEOC were not controlled by mass transfer process but by chemical reaction. Firstly, according to Brigante et al. $(2007)^{28)}$, the effect of mass transfer was normally weak in aqueous media especially under stirring condition; secondly, the activation energies $\left(E_{a p p}\right)$ were various with different compounds and showed higher values when they were related to chemical reaction control process ${ }^{29)}$. The results also indicated that the activation energy $\left(E_{\text {app }}\right)$ for the dissolving of slowly dissolving material was too high to be overcome by simply rising the aqueous temperature from $25{ }^{\circ} \mathrm{C}$ to $45^{\circ} \mathrm{C}$. The theory can be proved through the fact that increasing temperature (under the same $\mathrm{pH}$ condition) didn't lead to the rising of rapidly dissolving fraction and reducing $\mathrm{pH}$ value (under the same temperature condition) benefited for the rising of rapidly dissolving fraction (Table 2). On the other hand, the increasing leaching temperature leading to the increasing rate constant for the rapidly dissolving 

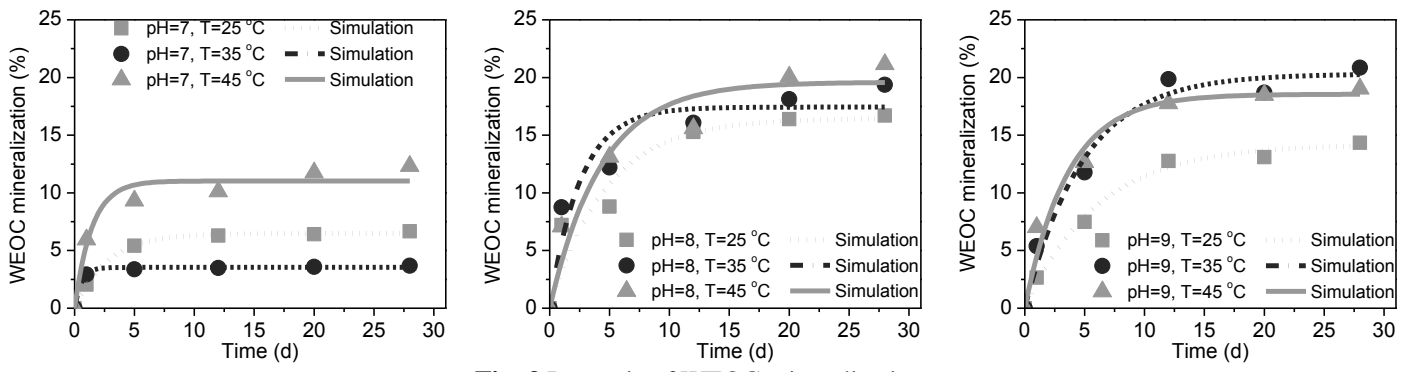

Fig. 3 Dynamic of WEOC mineralization.

Table 3. Results of dynamic analysis of WEOC biodegradation after 28 days' incubation.

\begin{tabular}{|c|c|c|c|c|c|c|c|c|c|c|c|c|}
\hline & \multicolumn{4}{|c|}{$\mathrm{T}=25^{\circ} \mathrm{C}$} & \multicolumn{4}{|c|}{$\mathrm{T}=35^{\circ} \mathrm{C}$} & \multicolumn{4}{|c|}{$\mathrm{T}=45^{\circ} \mathrm{C}$} \\
\hline & $\begin{array}{c}K_{1} \\
\left(d^{-1}\right)\end{array}$ & $\begin{array}{c}K_{2} \\
\left(10^{-18} d^{-1}\right)\end{array}$ & $\begin{array}{c}a \\
(\%)\end{array}$ & $R^{2}$ & $\begin{array}{c}K_{1} \\
\left(d^{-1}\right)\end{array}$ & $\begin{array}{c}K_{2} \\
\left(10^{-18} d^{-1}\right)\end{array}$ & $\begin{array}{c}a \\
(\%)\end{array}$ & $R^{2}$ & $\begin{array}{c}K_{1} \\
\left(d^{-1}\right)\end{array}$ & $\begin{array}{c}K_{2} \\
\left(10^{-18} d^{-1}\right)\end{array}$ & $\begin{array}{c}a \\
(\%)\end{array}$ & $R^{2}$ \\
\hline $\mathrm{pH}=7$ & 0.4 & 2.9 & 6.5 & 1.0 & 1.7 & 60.0 & 3.5 & 1.0 & 0.7 & 2.0 & 11.0 & 0.9 \\
\hline $\mathrm{pH}=8$ & 0.2 & 3.0 & 16.5 & 0.8 & 0.4 & $2 * 10^{-7}$ & 17.4 & 0.9 & 0.2 & 3.9 & 19.6 & 0.9 \\
\hline $\mathrm{pH}=9$ & 0.2 & 400.0 & 14.2 & 1.0 & 0.2 & 53.1 & 20.3 & 1.0 & 0.3 & 6.2 & 18.6 & 1.0 \\
\hline
\end{tabular}

fractions, $k_{f}$, was shown in Table 2. Therefore, the results obtained here suggested that, for our sample, the rising temperature (from $25{ }^{\circ} \mathrm{C}$ to $45^{\circ} \mathrm{C}$ ) mainly improved the dissolution rate of rapidly dissolving fraction which was controlled by physical adsorption/desorption process with the low activation energy ${ }^{29)}$ and extra energy was required to convert the slowly dissolving fraction of the sample into the rapidly dissolving fraction.

The dissolution behavior of organic carbon could be affected by both $\mathrm{pH}$ values and anions and cations concentrations ${ }^{30)}$. The cations concentrations after 6 hours' leaching experiment can be found in Table 4. The divalent cations concentration $\left(\mathrm{Mg}^{2+}\right.$, $\mathrm{Ca}^{2+}$ ) were dramatically increased when the $\mathrm{pH}$ decreased. The results obtained in the experiment were much different from other researches. Brigante et al.(2007, 2009) ${ }^{29,30)}$ found that dissolution rate of pure solid humic acid particles decreased by the inorganic divalent cations $\left(\mathrm{Mg}^{2+}, \mathrm{Ca}^{2+}, \mathrm{Sr}^{2+}, \mathrm{Ba}^{2+}\right)$. Different from the pure material, the material used in the leaching experiment was collected from field site. It contained more than $90 \%$ inorganic material. The decreasing $\mathrm{pH}$ values might accelerate the dissolving rate of the inorganic salt and therefore increased the concentrations of organic carbon in solid phase. The result can be proved by analyzing the TOCs before and after the leaching experiments (data not shown). Furthermore, inorganic salt might release the organic carbon captured in the particle or increase the contact area of the organic material and liquid phase which was beneficial for the dissolution rate.

The quality and biological nature of WEOC were affected by the extraction temperature. Normally, the amounts of biodegradable products under high temperature extraction condition exceed low temperature extraction amount ${ }^{31)}$. The results found in this experiment also support the theory mentioned above. The mineralization fraction of WEOC was ranging from $3.7 \%$ to $21.1 \%$ for all incubation experiments, which was similar to the range (12\%-20\% WEOC mineralization) found by Bu et al. $(2011)^{31)}$. The low decomposition rate constants of the stable WEOC, $k_{2}$, found in this experiment suggested that more than $79 \%$ of the WEOC was hard to be decomposed under anaerobic condition by in-situ bacteria. Moreover, based on the result found in this research, reduction of organic carbon from solid phase through water leaching was very low and the contribution of anaerobic mineralization of the WEOC to the TOCs reduction was liable to be negligible. However, much more leaching experiments with different types of MSW collected from different landfill are essential in order to further confirm this result.

Table 4. Cations concentrations after leaching experiment.

\begin{tabular}{ccccc}
\hline & $\begin{array}{c}\mathrm{Na}^{+} \\
(\mathrm{mg} / \mathrm{l})\end{array}$ & $\begin{array}{c}\mathrm{K}^{+} \\
(\mathrm{mg} / \mathrm{l})\end{array}$ & $\begin{array}{c}\mathrm{Mg}^{2+} \\
(\mathrm{mg} / \mathrm{l})\end{array}$ & $\begin{array}{c}\mathrm{Ca}^{2+} \\
(\mathrm{mg} / \mathrm{l})\end{array}$ \\
\hline $\mathrm{pH}=7, \mathrm{~T}=25^{\circ} \mathrm{C}$ & $4.1 \pm 0.3$ & $5.0 \pm 0.2$ & $5.1 \pm 0.1$ & $90.9 \pm 4.3$ \\
$\mathrm{pH}=7, \mathrm{~T}=35^{\circ} \mathrm{C}$ & $4.1 \pm 0.2$ & $3.4 \pm 0.3$ & $4.3 \pm 0.3$ & $82.3 \pm 5.5$ \\
$\mathrm{pH}=7, \mathrm{~T}=45^{\circ} \mathrm{C}$ & $4.4 \pm 0.4$ & $4.9 \pm 0.5$ & $4.3 \pm 0.4$ & $79.5 \pm 3.2$ \\
$\mathrm{pH}=8, \mathrm{~T}=25^{\circ} \mathrm{C}$ & $3.4 \pm 0.2$ & $4.8 \pm 0.2$ & $3.1 \pm 0.1$ & $44.7 \pm 7.1$ \\
$\mathrm{pH}=8, \mathrm{~T}=35^{\circ} \mathrm{C}$ & $3.4 \pm 0.3$ & $4.3 \pm 0.1$ & $3.1 \pm 0.1$ & $41.0 \pm 4.3$ \\
$\mathrm{pH}=8, \mathrm{~T}=45^{\circ} \mathrm{C}$ & $3.8 \pm 0.1$ & $3.5 \pm 0.4$ & $3.1 \pm 0.2$ & $39.3 \pm 4.2$ \\
$\mathrm{pH}=9, \mathrm{~T}=25^{\circ} \mathrm{C}$ & $3.3 \pm 0.2$ & $2.5 \pm 0.1$ & $2.4 \pm 0.1$ & $23.1 \pm 3.5$ \\
$\mathrm{pH}=9, \mathrm{~T}=35^{\circ} \mathrm{C}$ & $3.6 \pm 0.2$ & $3.1 \pm 0.2$ & $2.4 \pm 0.2$ & $24.2 \pm 4.1$ \\
$\mathrm{pH}=9, \mathrm{~T}=45^{\circ} \mathrm{C}$ & $3.6 \pm 0.1$ & $3.2 \pm 0.2$ & $2.4 \pm 0.3$ & $24.5 \pm 2.3$ \\
\hline
\end{tabular}




\section{Conclusions}

This study was conducted to investigate the dissolving behavior of MSW under various leaching conditions. Moreover, a dynamic model and two-compartment model have been used to interpret the leaching data. The biodegradability of WEOC was also estimated through the incubation experiment.

The results of this study showed that the equilibrium concentration of WEOC was increased with the reducing leaching $\mathrm{pH}$ values. The dissolve rates of organic carbon were in the order of $0.45-2.2 \times 10^{-1} \mathrm{~m}^{3} / \mathrm{kg} / \mathrm{h}$ for all leaching conditions. The dissolution rates of the solid sample are increasing while reducing the leaching $\mathrm{pH}$ values or increasing the leaching temperature. The $k_{f}$ values were in the order of 15-66 $\mathrm{h}^{-1}$, which were around 1000 times larger than $k_{s}$. It revealed that desorption behavior of organic carbon from MSW could be characterized by rapidly and slowly desorbing fractions. The value of rapid fraction $\left(f_{1}\right)$ increased with the reduction of liquid $\mathrm{pH}$ value and in the range of $30 \%-50 \%$. The maximum mineralization fractions was less than $21.1 \%$ suggesting that reduction of organic carbon from solid phase through water leaching was very low and the contribution of anaerobic mineralization of the WEOC to the TOCs reduction was liable to be negligible.

In spite of the results presented in this article, much work is still needed to achieve a good understanding on how $\mathrm{pH}$ value and temperature affect the separation of dissolvable fraction from the particles. The feasibility of aerobic bioremediation of the old landfill also needs to investigate.

\section{References}

1. Nguyen, N S., Soda, S., Sei, K., Ike, M.: Effect of Aeration on Stabilization of Organic Solid Waste and Microbial Population Dynamics in Lab-Scale Landfill Bioreactors. Journal of Bioscience and Bioengineering 106(5), 2008.

2. Ritzkowski, M., Stegmann, R.: Emission behaviour of aerated landfills: results of laboratory scale investigations. In: Proceedings Sardinia 2003, Ninth International Waste Management and Landfill Symposium, S. Margherita di Pula, Cagliari, Italy. 2003.

3. Hantsch, S., Michalzik, B., Bilitewski, B.: Different intensities of aeration and their effect on contaminant emission via the leachate pathway from old landfill waste - a laboratory scale study. In: Proceedings Sardinia 2003, Ninth International Waste Management and Landfill Symposium, S Margherita di Pula, Cagliari, Italy, 2003.

4, Cossu, R., Raga, R., Rossetti, D.: Full scale application of in situ aerobic stabilization of old landfills. In: Proceedings Sardinia 2003, Ninth International Waste Management and Landfill Symposium, S. Margherita di Pula, Cagliari, Italy, 2003.

5. Heyer, K U., Hupe, K., Ritzkowski, M., Stegmann, R.: Pollutant release and pollutant reduction: impact of the aeration of landfills. Waste Management 25 (4), 2005.

6. Jiao, G Z., Shimaoka, T., Komiya, T., Shi, X.: Examination on influence caused by air injection manners changing in Aerobic-Anaerobic landfill method. The fourth international symposium on the East Asian environmental problems 2010, pp.109-114, 2010

7. Blaser, P.: The role of natural organic matter in the dynamics of metals in forest soils. In: Senesi, N., Miano, T.M. (Eds.), Humic Substances in the Global Environment and Implications on Human Health. Elsevier, Amsterdam, pp. 943- 960,1994.

8. Marschner B, Kalbita K.: Controls of bioavailability and biodegradability of dissolved organic matter in soils. Geoderma 113(3-4), 211-235, 2003

9. Chantigny, M.H.: Dissolved and water-extractable organic matter in soils: a review on the influence of land use and management practice, Geoderma 113, 357-380, 2003.

10. Burford, J.R., Bremner, J.M.: Relation between denitrification capacities of soils and total water soluble and readily decomposable soil organic matter, Soil Biol. Biochem 7, 389-394, 1975.

11. Cook, B.D., Allen, D.L.: Dissolved organic carbon in old field soils: total amounts as a measure of available resources for soil mineralization. Soil Biol. Biochem 24, 585-594, 1992.

12. Six, J., Carpentier, A., van Kessel, C., Merckx, R., Harris, D. Horwarth, W.R., Lüscher, A.: Impact of elevated $\mathrm{CO}_{2}$ on soil organic matter dynamics as related to changes in aggregate turnover and residue quality. Plant and Soil 234, 27 - 36, 2001.

13. Zmora-Nahum, S., Markovitch, O., Tarchitzky, J., Chen, Y.: Dissolved organic carbon (DOC) as a parameter of compost maturity. Soil Biology and Biochemistry 37, 2109 - 2116, 2005.

14. Northcott GL, Jones KC.: Partitioning, extractability, and formation of nonextractable PAH residues in soil. 2. Effects on compound dissolution behavior. Environ Sci Technol 35:1111-1117,2001.

15. Ghosh U, Weber AS, Jensen JN, Smith JR.: Relationship between PCB desorption equilibrium, kinetics, and availability during land biotreatment. Environ Sci Technol 34:2542-2548, 2000 .

16. Chai, X., Hao, Y., Shimaoka, T., Nakayama, H., Komiya, T., Zhao, Y.: The effect of aeration position on the spatial distribution and reduction of pollutants in the landfill stabilization process-a pilot scale study. Waste Management and Research (accepted).

17. Japanese Environmental Agency (1995) Departmental notification No.46, 1995 on leaching test method for soils (in Japanese); Japanese official regulation.

18. Wu, S., Gschwend, P. M.: Sorption kinetics of hydrophobic organic compounds to natural sediments and soils. Environ. Sci. Technol. 20, 717-725, 1986.

19. Johnson, M.D., Keinath, T.M., Weber, W.J.: A Distributed Reactivity Model for Sorption by Soils and Sediments. 14. Characterization and Modeling of Phenanthrene Desorption Rates. Environ. Sci. Technol. 35, 1688-1695, 2001.

20. Cornelissen, G., Rigterink, H., Frerdinand, M.M.A., Van Noort, P.C.M.: Rapidly Desorbing Fractions of PAHs in Contaminated Sediments as a Predictor of the Extent of Bioremediation. Environ. Sci. Technol. 32, 966-970,1998.

21. Shao, Z.H., He, P.J., Zhang, D.Q., Shao, L.M.: Characterization of water-extractable organic matter during the biostabilization of municipal solid waste. J. Hazard. Mater., 164, 1191 - 1197,2009.

22. Zsolnay, A.: Dissolved organic matter: artefacts, definitions, and functions. Geoderma 113, 187-209, 2003.

23. Kalbitz, K., Schmerwitz, J., Schwesig, D., Matzner, E.: Biodegradation of soil derived dissolved organic matter as related to its properties. Geoderma 113, 273-291, 2003.

24. McDowell, W.H., Zsolnay, A., Aitkenhead-Peterson, J.A., Gregorich, E.G., Jones, D.L., Jodemann, D., Kalbitz, K., 
Marschner, B., Schwesig, D.: A comparison of methods to determine the biodegradable dissolved organic carbon from different terrestrial sources. Soil Biology and Biochemistry. 38 . 1933-1942, 2006.

25. Zhao, M., Zhou, J., Kalbitz, K.: Carbon mineralization and properties of water-extractable organic carbon in soils of the south Loess Plateau in china. European Journal of Soil Biology. 44, 158-165, 2008.

26. Namour, P., Muller, M.C.: Fractionation of organic matter from wastewater treatment plants before and after a 21 day biodegradability test: a physical-chemical method for measurement of the refractory part of effluents. Water research. 32, 2224-2231, 1998.

27. Don, A., Kalbitz, K.: Amount and degradability of dissolved organic carbon from foliar litter at different decomposition stages Soil Biology and Biochemistry. 37. 2171-2179, 2005.
28. Brigante, M., Zanini, G., Avena, M.: On the dissolution kinetics of humic acid particles: Effect of $\mathrm{pH}$, temperature and $\mathrm{Ca}^{2+}$ concentration. Colloids and Surfaces A: Physicochem. Eng. Aspects 294, 64-70,2007.

29. Sparks, D.L.: Sorption-desorption, kinetics. In Encyclopedia of Soils in the Environment, p. 556-561, 2005.

30. Brigante, M., Zanini, G., Avena, M.:, Effect of pH, anions and cations on the dissolution kinetics of humic acid particles. Colloids and Surfaces A: Physicochem. Eng. Aspects 347, 180-186, 2009.

31. Bu, X., Ding, J., Wang, L., Yu, X., Huang, W., Ruan, H.: Biodegradation and chemical characteristics of hot-water extractable organic matter from soils under four different vegetation types in the Wuyi Mountains, southeastern China. European Journal of Soil Biology 47, 102-107, 2011.

(Received May 25, 2012) 